\title{
Personalized medicine in patients with Osteogenesis imperfecta
}

\author{
Oliver Semler ${ }^{*}$, Heike Hoyer-Kuhn, Joerg Doetsch, Eckhard Schoenau \\ From 50th Workshop for Pediatric Research \\ Gottingen, Germany. 20-21 March 2014
}

\section{Background}

Due to an expanding knowledge about the molecular diversity the disease Osteogenesis imperfecta (OI), formerly known to be a disorder of the collagen synthesis, changed to a group of disorders with a fragile skeleton as common symptom. Patients with OI type VI are clinically characterized by an increased amount of osteoid and a poor response to bisphosphonate treatment.

\section{Patients}

In two boys with signs of OI we identified the disease causing mutation of OI VI [1]. Mutations in SERPINF1 lead to the absence of pigment epithelium derived factor (PEDF), which is a key factor for the regulation of osteoclastogenesis. Without PEDF the differentiation of preosteoclasts is increased and more bone will be resorbed.

\section{Consequence}

Due to the new understanding of the pathophysiology of OI VI we decided to target the osteoclasts directly using the Rankl-antibody Denosumab. This was the first use of Denosumab in children.

\section{Results}

With this change of therapy we were able to reduce bone resorption to the normal range [2].

After two years of treatment both patients show an increase of bone mineral density of the lumbar spine with a $\mathrm{z}$-score from -2.4 to -2.0 and -4.3 to 2.5 respectively and an increase of projected vertebral area $\mathrm{L} 2-\mathrm{L} 4\left[\mathrm{~mm}^{2}\right]$ from 1670 to 2152 and from 1424 to 1528 . No severe side effects were seen and the drop of serum calcium after the subcutaneous injection could be treated by oral calcium supplementation.

\section{Conclusion}

Clinical observation and molecular analysis lead to a new understanding of OI VI and to a more specific therapeutic approach. The new therapy resulted in a better therapeutic effect and is a striking example of a fast transfer from basic research to therapeutic use.

Published: 11 September 2014

\section{References}

1. Becker J, et al: Am J Hum Genet 2011, 88(3):362-71.

2. Semler O, et al: J Musculoskelet Neuronal Interact 2012, 12(3):183-8.

doi:10.1186/2194-7791-1-S1-A10

Cite this article as: Semler et al: Personalized medicine in patients with Osteogenesis imperfecta. Molecular and Cellular Pediatrics 2014 1(Suppl 1): A10.

Children's Hospital, University Cologne, Cologne, Germany

Submit your manuscript to a SpringerOpen ${ }^{\circ}$ journal and benefit from:

- Convenient online submission

- Rigorous peer review

- Immediate publication on acceptance

- Open access: articles freely available online

- High visibility within the field

- Retaining the copyright to your article

Submit your next manuscript at $\boldsymbol{\triangleright}$ springeropen.com 